\title{
EVOLUCIÓN Y BIODIVERSIDAD: LA IMPORTANCIA DE LA BIOLOGÍA SISTEMÁTICA
}

\section{EVOLUTION AND BIODIVERSITY: THE IMPORTANCE OF SYSTEMATIC BIOLOGY}

\section{AUTORES}

José María Barrasa. Universidad de Alcalá. Profesor Titular del Departamento de Biología Vegetal

josem.barrasa@uah.es

\section{CURRICULUM VITAE}

Profesor en la Facultad de Biología. Universidad de Alcalá de Henares.

\section{RESUMEN}

La evolución y la biodiversidad son objeto de estudio de la Biología Sistemática, una rama de la Biología que sorprendentemente se encuentra hoy olvidada y desprestigiada debido, probablemente, a que las nuevas tecnologías han aupado y encumbrado otras disciplinas como la Biología molecular, la Biotecnología o la Ingeniería genética argumentando un carácter más aplicado.

\section{PALABRAS CLAVE}

Evolución - Biodiversidad - Biología sistemática 


\section{ABSTRACT}

The evolution and biodiversity are being studied for Systematic Biology, a branch of biology that is surprisingly neglected and discredited today, probably due to new technologies have moved it and lifted other disciplines such as molecular biology, biotechnology or genetic Engineering arguing a more applied.

\section{KEY WORDS}

Evolution - Biodiversity - Systematic Biology

La evolución y la biodiversidad son objeto de estudio de la Biología Sistemática, una rama de la Biología que sorprendentemente se encuentra hoy olvidada y desprestigiada debido, probablemente, a que las nuevas tecnologías han aupado y encumbrado otras disciplinas como la Biología molecular, la Biotecnología o la Ingeniería genética argumentando un carácter más aplicado.

Una de las especialidades (orientaciones, itinerarios...) que en su día se propusieron para el plan nuevo (o adaptado) de Biología en nuestra universidad, llevaba precisamente la denominación de Evolución y Biodiversidad. Independientemente de cuál sea el destino definitivo de dicha especialidad en los futuros estudios de Biología, quisiéramos, en este breve ensayo, enfatizar el interés (y también el carácter aplicado) que tal orientación posee, así como reclamar el lugar que le corresponde a la Sistemática biológica dentro del marco conceptual de la Biología. 
El resultado de la evolución es la extraordinaria diversidad de seres vivos y ecosistemas existentes y la aún más extraordinaria diversidad de los seres vivos y ecosistemas desaparecidos en el transcurso de la historia de la Tierra.

Nuestro conocimiento sobre diversidad ecológica es aún muy escaso y queda mucho por averiguar sobre la diversidad de las biotas y ecosistemas actuales y sus relaciones evolutivas entre ellos y con los ya extinguidos. Éste es aún un aspecto pendiente que los ecólogos han comenzado ya a tratar, y que sin duda constituye un enorme campo de investigación que la Ecología del momento actual deberá desarrollar.

Algo mayor es el conocimiento que poseemos sobre diversidad biológica, es decir, la diversidad relativa a genealogía. Se ha calculado que las estirpes vivientes suponen un pequeñísimo porcentaje de las que han existido a lo largo de los 3500-4000 millones de años que lleva la vida instalada en nuestro planeta. En cuanto a la diversidad actual disponemos de un catálogo aproximado de 1.800 .000 especies descritas, pero las estimaciones de la diversidad biológica real van mucho más lejos; por ejemplo se calcula que existen entre 350.000 y 600.000 especies de plantas terrestres y entre $5 \mathrm{y}$ tal vez 30 millones de especies animales.

El manejo de tanta información acumulada sobre los seres vivos conocidos, presentes y pretéritos, y de la mucha más que aún nos queda por descubrir, requiere de sistemas de recopilación y de clasificación eficaces, que permitan su fácil recuperación. De ello se ocupan las disciplinas del campo de la Sistemática. Ésta que cuenta ahora con una sólida base teórica, proporcionada por la ciencia de la evolución, es también una ciencia viva, cambiante, ya que los nuevos conocimientos que incorpora, obligan en ocasiones a modificar los grupos establecidos, al proporcionar nuevas evidencias, nuevas hipótesis o nuevas interpretaciones, a la vez que ofrece clasificaciones más fiables. 
El empeño de la Sistemática moderna es la elaboración de sistemas clasificatorios que reflejen la evolución y la filogenia de los seres vivos, y ello porque sólo el Sistema Evolutivo es el que contiene mayor cantidad de información y del que se recupera con mayor facilidad, ya que no solo proporciona una visión de conjunto de los seres vivos sino que permite la obtención de generalizaciones, la repetitividad de las experiencias y la predicción de los resultados de un experimento.

Entendemos que la Sistemática es la más elemental y la más inclusiva de las ciencias biológicas: elemental porque estudia directamente a los seres vivos e inclusiva porque reúne e implementa cada dato que se descubre de éstos. En la medida en que la Biología Sistemática es recopiladora, es también la única de las ciencias que se ocupa de la biodiversidad ya que dispone del cuadro completo de la naturaleza. El manejo multidimensional de todos los datos de la Biología le permite tener una visión de conjunto que falta en las disciplinas particulares de la Biología Funcional, donde el mecanicismo reduccionista suele ser normal.

La Biología Sistemática es a la vez una ciencia básica y auxiliar. Es una ciencia básica porque debe hacer una descripción de la parte del universo que le corresponde, pero es también una ciencia auxiliar en tanto que proporciona el Inventario de la diversidad biológica. Este inventario es de enorme importancia y utilidad, ya que aporta una valiosa relación de los objetos de estudio para cualquier otra disciplina, no ya sólo de las pertenecientes a la Biología funcional, sino también a cualquiera de las otras ciencias no biológicas.

La Biología Sistemática es, además, un compendio básico para la gestión ambiental de los recursos biológicos, que debe comenzar por conocer qué y cómo es lo que ha de gestionar. Sin embargo, sólo las disciplinas de las Ciencias Biológicas otorgan ese conocimiento adecuado y completo del mundo vivo que se obtiene desde el enfoque de la Biología Funcional y, más aún, desde el de la Biología Sistemática. Conviene 
aclarar aquí, que el término Medioambiente, ahora de uso tan frecuente pero nunca bien definido, no significa más que el resultado de las numerosas interacciones que los seres vivos establecen entre sí y con el medio físico. Se habla también de medioambiente global cuando se considera a todo el planeta (incluyendo biosfera, hidrosfera, atmósfera y litosfera) como un único y gran ecosistema. Creemos que una adecuada gestión medioambiental debe emanar del saber adquirido en la materia y del entendimiento y diálogo entre las diferentes disciplinas científicas implicadas en su estudio. Así, debe ser competencia de la Ciencia de la Biología (incluyendo la Ecología), en conexión con otras ciencias no biológicas más relacionadas con el medio abiótico como la Química, la Física y la Geología, y otras de índole social como la Economía o la Sociología.

Las recién nacidas y mal denominadas Ciencias Ambientales, creadas artificialmente al amparo de la moda ambientalista, pretenden asumir la gestión del medioambiente y los recursos del planeta a partir de los informes científicos elaborados por las disciplinas científicas antes mencionadas. Creemos que su actuación carece del método y desarrollo científicos adecuados, y queda así restringida a la mera gestión de algo que ni siquiera conoce (ni puede conocer) debido a la enorme complejidad de cada una de las materias implicadas. En nuestra opinión, las Ciencias Ambientales nunca podrán constituir una Ciencia como tal y la gestión medioambiental, como cualquier gestión de otra índole, sólo podrá correr a cargo de un conjunto de conocedores de la materia o materias que hay que gestionar.

La Biología Sistemática provee también de nombres inequívocos y de la precisión terminológica necesaria para la comunicación. Elabora claves de identificación, imprescindibles para estudios de biodiversidad zonal, planificación del territorio, reconocimiento de plagas etc. Aporta el Sistema de Clasificación, marco de referencia imprescindible para cualquier trabajo científico relacionado con los seres vivos, sea de fisiología, genética, ecología, etc. Del Sistema se parte y a él se vuelve para 
incorporar los nuevos datos aportados por todas las disciplinas biológicas; sin sistema cualquier descubrimiento carecería de sentido. La clasificación hace a la diversidad biológica accesible a la comunidad científica en general, a la encargada de la gestión del Planeta y al hombre de la calle. Por último, realiza la reconstrucción de la filogenia, ayudando a desarrollar la Teoría Biológica.

La Sistemática no solo nos describe la realidad del mundo vivo, sino que contribuye con sus aportaciones al mejor conocimiento de la estructura de las especies. Éstas se componen de poblaciones que se distribuyen en el espacio y constituyen así las diferentes biotas del globo. Además, los patrones de distribución de los linajes o estirpes se han llegado a conocer gracias a los sistemáticos, y son de alto valor para la teoría de la evolución. Cuando comparamos varias estirpes y observamos que cada una de ellas tiene una serie de caracteres propios y, a la vez, caracteres compartidos con otras estirpes diferentes $y$, además, conocemos las causas biológicas tanto de lo compartido como de lo diferencial, nos damos cuenta de que la Sistemática nos revela importantes fenómenos evolutivos. Por ejemplo, recientemente se ha descubierto que en el linaje de los Gnetófitos (un interesante grupo de plantas, tradicionalmente consideradas Gimnospermas, que comprende sólo tres géneros en el mundo: Ephedra, Weltwitschia y Gnetum), tiene lugar el fenómeno de la doble fecundación, hasta hace poco conocido exclusivamente en Angiospermas. Dicho fenómeno se ha descrito en Ephedra (Friedman, 1990, Science, 47:951-954 y Friedman,1991, Protoplasma, 165:106-120) y en Gnetum (Carmichael et al., 1996, Am. J. Bot., 83:767-780). En esencia consiste en que uno de los dos núcleos del tubo polínico fecunda a la ovocélula del saco embrionario para formar el embrión, mientras el otro núcleo fecunda a los núcleos polares del saco embrionario para formar el tejido nutricio. A su vez, éste tejido alimentará al embrión durante la formación de la semilla. Sin embargo, ambos linajes, Gnetófitos y Angiospermas, difieren en que en los primeros la doble fecundación no va acompañada de la formación de tejido nutricio (o endospermo triploide) y en los segundos sí. Ahora se 
sabe que la doble fecundación es un carácter compartido por Gnetófitos y Angiospermas, y que éste carácter debió ser heredado de un ancestro común de ambos linajes, mientras que la formación del endospermo triploide permanece como carácter derivado y exclusivo de Angiospermas al que algunos autores atribuyen la causa del "éxito" evolutivo que actualmente muestra este grupo de plantas. En base a ello, la Ciencia de la Sistemática, al establecer la clasificación, sitúa ya a ambos linajes claramente emparentados, reflejando así sus relaciones evolutivas (Doyle and Donoghue, 1992, Brittonia, 44: 89-106; Doyle, 1996, Int. J. Plant Sci., 157, 6 suppl: S3S39).

Vemos pues, que la investigación de las comunidades de descendencia aporta reflexiones acerca de las causas del cambio evolutivo, modos de especiación, actuación de la selección natural etc., con lo que igualmente contribuye al desarrollo de la teoría evolutiva.

El Sistema Evolutivo es una inagotable fuente de hipótesis, basadas en las relaciones de parentesco entre estirpes y en el conocimiento integrado de sus características biológicas. El valor predictivo que posee, tanto más alto cuanto mejor elaborado esté, permite la investigación dirigida y consciente en el seno de las disciplinas aplicadas. Por ejemplo, conociendo las relaciones de competencia entre hongos y bacterias, la búsqueda de antibióticos será fructífera mediante el estudio del metabolismo de aquellos antes que de otros grupos. También, si se desea obtener un fármaco identificado en una especie rara, cabe buscarlo entre las especies hermanas más abundantes. El conocimiento de las relaciones entre especies proporciona las bases para la lucha contra plagas y, el de las relaciones intraespecíficas permite la mejora de las razas de cultivo o de cría, cuyos parientes silvestres suelen poseer genes deseables que, cuando se incorporan en aquellas, permiten obtener una productividad más alta o bien mayor resistencia al frío, sequía, infecciones, etc. 
La Sistemática pues, proporciona aplicaciones directas de sus conocimientos en el campo de la Medicina, Veterinaria, Agricultura, Ganadería y Economía. Es una parte de la Biología básica que se nutre de las aportaciones de todas las disciplinas biológicas, a la vez que les proporciona su razón de ser. Es fundamental para la Investigación Biológica y es fundamental para la conservación y gestión de los recursos de la Biosfera. 